\title{
Research on the Training Mode of Innovative and Entrepreneurial Talents in Colleges and Universities from the Perspective of Regional Economic Development
}

\author{
Li Gang $^{1, a}$, Zhong Lijun ${ }^{1, b}$ and Li Jingli ${ }^{2,, *}$ \\ ${ }^{1}$ School of Mechanical Engineering, Baicheng Normal University, Jilin, Baicheng, 137000, China \\ ${ }^{2}$ School of Marxism, Baicheng Normal University, Jilin, Baicheng, 137000, China \\ a20905612@qq.com, b254170945@qq.com, 337453323@qq.com \\ *corresponding author: LI Jingli, 337453323@qq.com
}

Keywords: Regional economy, Innovative entrepreneurial talent training, Colleges and universities, Collaborative development.

\begin{abstract}
The cultivation of innovative talents is the direction of the future reform and development of higher education in China, the main driving force to promote the development of national modernization economy, and also an important resource to promote the development of local economy. At present, the cultivation of innovative talents in Colleges and universities can't meet the needs of regional economic development, which is the main problem faced by local colleges and universities. This paper expounds the significance of innovating the talent cultivation mode of colleges and universities in promoting regional economic development, and analyzes the problems existing in the talent cultivation mode of colleges and Universities Serving Regional Economic development. In order to serve the regional economic development better and promote the better coordinated development of both sides, this paper puts forward the construction method of the cultivation mode of innovative talents in Colleges and universities facing the regional economic development.
\end{abstract}

\section{Introduction}

The regional economic and social needs are the support of the development of talents in colleges and universities. Talent training is the support and motive force of regional economic and social needs. Therefore, personnel training and regional economic and social needs Is mutual cooperation, mutual restraint, and only coordination can achieve common development. In order to achieve common development, the training of talents in colleges and universities must be integrated into the overall planning of economic development and social demand, improve the mode of higher education personnel training, improve the innovation and entrepreneurial ability of college students. Adhere to the principle of moderately advanced development, to scientific positioning, to do the characteristics of personnel training to take the initiative to adapt to regional economic construction and social development needs, and establish a sense of economic development services ${ }^{[1]}$.

\section{The significance of cultivating innovative and entrepreneurial talents in colleges and universities}

China's comprehensive reform of entrepreneurship education in China from 2015, China nearly three years each year more than 700 million college graduates to the community, to promote "public entrepreneurship and innovation", inseparable from the most dynamic college students, has become consensus. However, the annual number of business students in the business sector registration of not more than 600,000 , the proportion of innovation and entrepreneurship compared to the developed countries there is still a big gap. And with the development of regional economy, the current pattern of personnel training in colleges and universities in our country gradually shows the limitations, especially with the regional economic development for the demand for talent there is a 
considerable gap, highlighted as the demand for economic and social development out of touch. Innovative talents are the most fundamental elements of innovation-driven development. It is also the most direct driving force for the development of society, economy, culture and science and technology. It is also the strategic goal put forward by the country to cultivate innovative and entrepreneurial talents. Colleges and universities constitute an important part of the national innovation system, shoulder the responsibility of knowledge transmission, innovation and application, and thus should be innovative spirit of innovation and entrepreneurship training as a responsibility. To serve the regional economic development as the starting point, to actively cultivate innovative entrepreneurial talents for the purpose of running a school, focus on training to adapt to regional economic development of innovative entrepreneurial talent, effectively solve the current students "employment difficulties" and corporate "recruitment difficult" contradiction ${ }^{[2]}$.

\section{The problems of cultivating innovative and entrepreneurial talents in colleges and universities}

In the process of cultivating innovative talents, colleges and universities have achieved certain achievements, but because of the constraints of traditional culture and examination-oriented education system, the talents and practical ability of cultivating talents are not strong. China's current innovation and entrepreneurial talent training level and talent situation, can't fully adapt to the country's development strategy and economic and social development needs. Over the years, China's innovation and entrepreneurship in the process of training there are some problems ${ }^{[3]}$.

\subsection{University of the service area of economic and social development of the responsibility and awareness is not in place}

Although some colleges and universities put forward to serve the regional social and economic development, but their own sense of service is not in place, the development of colleges and their own development and the relationship between regional economic development is not properly understood, nor properly handle the university personnel training and regional economic society The relationship between demand, the lack of regional economic development and social development services to the sense of ownership. Therefore, the lack of adequate attention to the multi-type, multi-standard and high-quality personnel training in serving the regional economic development can affect the benign interaction and cooperative development of the two sides to a certain extent ${ }^{[4]}$.

\subsection{Discipline professional structure and regional economic structure development is not coordinated}

At present, China's colleges and universities are constantly in the discipline and professional structure of the adjustment, the discipline system construction, but the new professional structure and discipline system has not yet established and improved, for example, the proportion of new applied disciplines than the traditional basic disciplines The proportion is still very far away, in addition, in the discipline, especially the new discipline curriculum, teaching methods, the use of the carrier, the teaching equipment required for the conditions and conditions and teachers are equipped with unreasonable and inadequate, Thus, in this imperfect discipline system and structure under the training of personnel are low and low level, can't be well adapted to regional economic and social development ${ }^{[5]}$.

\subsection{Creative Entrepreneurship Education and Separation of Professional Education}

At present, China's colleges and universities mainly to professional education, colleges and universities based on professional personnel training program, in accordance with the set of curriculum system to implement professional education. Therefore, in order to innovative entrepreneurship education and professional education science and reasonable integration, not only to increase the number of innovative entrepreneurship courses, but should be in the professional training programs and curriculum system in all aspects of innovation into the concept of 
entrepreneurship education The However, the majority of colleges and universities in China is not comprehensive understanding of innovation and entrepreneurship education, innovation and entrepreneurship is not the diversification of talent into the professional education of personnel training system, innovative entrepreneurship education and professional education is not close, independent set of innovative business The relationship between educational curriculum and professional learning is not even independent of each other, leading to the separation of innovative entrepreneurship education and professional education. Students' innovative business knowledge and professional knowledge exist independently in the mind and can't be played in practice. Education and market demand and social demand for talent is difficult to effectively integrate ${ }^{[6]}$.

\subsection{The cooperative mechanism between universities and local governments and enterprises is imperfect}

Although the Ministry of Education launched the "Higher Education Innovation Enhancement Program", but the current cooperation between universities and local governments and enterprises mechanism is not sound enough. Some colleges are not aware of this. Although some colleges and universities aware of this, with local governments and enterprises to cooperate, interactive and mutual development, but the scale of cooperation and interactive development are relatively small. The areas of interaction between the three are relatively narrow, the level of cooperation is not high, the channels of cooperation and cooperation are not smooth, especially long-term, centralized cooperation is seriously inadequate, long-term cooperation mechanism has not yet been established. Colleges and universities can't accurately grasp the information needed to promote regional development of talent, so that the university's own personnel training policies and measures on the market lack of rapid and accurate response is not conducive to the timely adjustment of personnel training $^{[7]}$.

\section{Measures of Cultivating Innovative Entrepreneurship Talents in Colleges and Universities}

\subsection{Clearly cultivate the goal, construct innovative and innovative talents training program}

To carry out the "student-oriented, quality school, academic simultaneously " concept of running a school, in-depth exploration of "strong adaptability and practical ability of innovative entrepreneurial talent" training law, conscientiously sum up school experience, Teaching research results and successful school experience to solidify the training program. In order to cultivate the goal of innovation and entrepreneurial talents, this paper constructs a training program with certain characteristics and forward-looking talents, which is based on the goal of "wide caliber, broad foundation, wide adaptability and strong ability" ${ }^{18]}$.

\subsection{Strengthening the Practical Teaching Links, Constructing the Practical Teaching Mode of Students' Application Ability and Innovating Entrepreneurship}

Practical teaching is the most direct and effective way to cultivate students' ability of innovation and entrepreneurship, and play a key role in the cultivation of applied talents. The school should aim at cultivating students' practical ability, strengthen the practice teaching links, promote the reform and innovation of experimental contents and experimental models, improve the quality of experimental teaching, reform the graduation thesis (design), promote the practical application of graduation thesis, System construction to create conditions to support and organize students to actively carry out social practice and college students science and technology competition, professional competition activities, participate in scientific research, innovative experiments and practice to enhance students' innovative spirit and innovation ability ${ }^{[9]}$.

\subsection{To improve students' ability of autonomous learning, practical ability and innovative awareness of the ways and means}

Build a scientific, reasonable and operable personnel training system. How to cultivate students 'innovative consciousness and how to cultivate the innovation consciousness and practical ability of college students through the teaching links such as graduation design and so on, and how to 
cultivate students' innovative consciousness and teaching ability. On the basis of this, with the innovation and entrepreneurship education reform as the breakthrough point, deepen the reform of education and teaching in colleges and universities, improve the training mode of practical talents, and further improve the teaching level and the quality of personnel training.

\subsection{Exploring the training mode of collaborative talents between universities and regional enterprises}

The development of colleges and universities and the direction of personnel training are closely related to the development of local social economy, culture and science and technology. Colleges and universities should closely integrate with the local social and economic development needs, establish the school for the use of school thinking, Strengthen cooperation with local governments and enterprises, and strengthen the coordination of personnel training. It is not only possible to solve the problems existing in local development, but also can effectively improve the quality and comprehensive strength of the personnel training in colleges and universities so as to achieve the effective integration of resources and form the coordination of multiple models. Innovation, interaction and win-win, the establishment of innovative personnel training model and dynamic mechanism to improve the quality of innovative entrepreneurship training ${ }^{[10]}$.

\section{Conclusion}

Deepening the reform of innovation and entrepreneurship education for colleges and universities, national implementation of innovation driven development strategy, promote the urgent need to upgrade the quality and efficiency of economic, is to promote the comprehensive reform of higher education and promote college graduates more high quality employment and Entrepreneurship of important initiatives. It is a long-term and arduous big project to cultivate innovative talents training mode which is suitable for the regional economic development. It is a long-term and arduous big project that needs to be multi- Angle to carry out in-depth research and exploration.

\section{Acknowledgements}

This work was partly supported by the Jilin Provincial Department of Education Humanities and Social Sciences Research Project (project Number: Ji Jiao Ke Wen He Zi [2016] No. 15) and Jilin Provincial Department of Education vocational education and adult education reform research project in 2016 (project Number: 2016ZCY002).

\section{References}

[1] LUO Ying, MA Li, YOU Xiao-xia. On the Cultivation of Innovative Talents in Local Colleges and Universities Under the Perspective of Regional Economic Development[J]. Education Exploration, 2014(6):83-84.

[2] LIU Ying. Research on the Innovation and Entrepreneurship Personnel Training Mode in Science and Engineering Colleges[D]. Harbin University of Science and Technology, 2015.

[3] GUO Lili. Talent Cultivation in Colleges and Universities for Serving Development of Regional Economy[J]. Journal of Shenyang University, 2015(8):520-522.

[4] YANG Feng, WANG Liqing. An Exploration of Innovative Talents Cultivation Model in Jilin Universities to Adapt to Economic Development[J]. Oriental Enterprise Culture, 2014 (23).

[5] LIU Yunpeng, YU Guangxu, ZHANG Fuyu. Exploration on the Cultivation of Innovative Talents in Local Colleges and Universities from the Perspective of Collaborative Innovation[J]. Journal of ZHONGZHOU University, 2016(6):101-104.

[6] XIAO Le. A Study of the Applied Undergraduates Cultivating in the Local Colleges and Universities[D]. HUBEI University of Technology, 2017.

[7] LIU Xiaohua. The Cooperative Development of Innovation and Entrepreneurship Education and Regional Economy in Local Colleges[J]. Journal of Zunyi Normal University, 2018(3):50-52. 
[8] ZHANG Rong. Promoting the Coordinated Development of Innovation and Entrepreneurship Education in Colleges and Universities and Regional Economy[J]. CHINA HIGHER EDUCATION, 2017(23):37-39.

[9] LI GANG, LI Jingli. The Exploration Study of the Application of Innovative Talents Training Mode in Colleges and Universities[J]. Journal of Baicheng Normal University, 2017(6):61-63.

[10] LEI Li. THE ROLE OF REGIONAL DEVELOPMENT AND INNOVATION OF LACAL COLLEGES AND IMOVERSOTOES IN JILIN[D]. YANBIAN UNIVERSITY, 2013. 